\author{
Boyan TODOROV ${ }^{1 *}$, Miroslava NEDYALKOVA ${ }^{1}$ and Vasil SIMEONOV ${ }^{1}$
}

\title{
ENVIRONMENTAL EFFECT OF POTENTIAL RADIOPHARMACEUTICALS RESIDUALS
}

\begin{abstract}
Driven by the current development of quantitative structure-properties relationship (QSPR) methods in the environmental science, we proposed an approach based on chemometric tools for selection of appropriate physicochemical parameters of radiopharmaceuticals residuals for predicting of partitioning, hazards and biodegradation of such compounds into the environment or into wastewater treatment plant. The present scheme was successfully applied for prediction of missing values for 24 different physicochemical and assessment response of the environmental fate descriptors for 11 tetrazine derivatives and 12 cyclooctene derivatives. The multivariate statistics was also proved to be useful in the evaluation of the obtained modelling results for identification of the ecological effect of radiopharmaceuticals residuals. The presented approach can be one of the first steps and support tools in the assessment of chemicals in terms of their environmental impact. The problem studies are significant since it allows a special point of view to the underestimated radiopharmaceutical pollutants.
\end{abstract}

Keywords: radiopharmaceutical residual, chemometrics, biodegradation

\section{Introduction}

Pharmaceuticals are a specific type of environmental pollutant (micropollutants) with various detrimental effects on the ecosystem [1,2]. An interesting representative of this category are radiopharmaceuticals (RP) which are routinely administered worldwide in the form of nuclear medicine for therapeutic and diagnostic purposes [3, 4]. As a result of all medical disposal, radioactive effluents can reach wastewater treatment plants (WWTP) and these facts are well-known to public bodies concerned with the release of artificial isotopes into the environment [5]. After the administration of RP are incorporated into the patient's body via different routes depending on the examination, and one of the excretion pathways is urine, radionuclides generally reach the sewer system. This can be done by discharging the patient directly if a diagnostic dose is administered, or after radioactively decaying in hospital waste storage tanks if the patient remains in hospital after therapeutic treatment [6]. Radionuclides applied in nuclear medicine and their transport in the sewage system have been the subject of many researches, sewage effluent and sludge activity concentrations in different WWTP were determined [7-12]. In these studies, many conclude that, once radionuclides have entered WWTP, some of them may associate and bind to organic particles settled during the water treatment process. This knowledge opens up the possibility to design and apply prognostic models to foresee effluent activity concentrations $[13,14]$. These models depend on a number of biochemical parameters but take into

\footnotetext{
${ }^{1}$ Faculty of Chemistry and Pharmacy, University of Sofia "St. Kl. Okhridski", 1, J. Bauchier blvd., 1164, Sofia, Bulgaria, email: b.todorov@chem.uni-sofia.bg,nhmn@chem.uni-sofia.bg,vsimeonov@chem.uni-sofia.bg *Corresponding author: b.todorov@chem.uni-sofia.bg
} 
account only the chemical form of radioisotopes as a single element, neglecting the non-radioactive part of RP.

The majority of currently available RP are composed of three main components: a targeting biomolecule (bio-vector), the bifunctional agent (conjugation, pharmacokinetic), and the radioisotope (therapy or diagnostic) $[15,16]$. Carrying out environmental impact studies using existing models [17, 18] will provide reliable data about environmental behaviour of the radionuclides without information for the effect of their non-radioactive part. This organic part of RP can be accepted as radiopharmaceutical residuals (RPR) which will cause for longer time effect on nature $[19,20]$ than conjugated radioisotopes (short half-lives from minutes to days). The plethora of existing bifunctional agents [21] responsible for conjugation of radioisotopes and bioactive molecules will provoke more different behaviour of RP in WWTP or in exact ecosystem than restricted number of suitable for nuclear medicine radioisotopes [3]. Keeping in mind very low concentrations of RPR in natural samples and followed instrumental straits [19, 22] application of computational methods for predicting environmental behaviour are very appropriate.

Knowing partition between n-octanol and water or $\log K_{\mathrm{ow}}$ is possible to predict the properties of organic compounds. $\log K_{\text {ow }}$ has been used to develop quantitative structure-property relationships (QSPRs) for predicting the water solubility [23, 24], toxicity [25, 26], soil-water partitioning [27], sorption coefficients [28, 29] and effects of organic compounds on the environment and human health. Combinations of these parameters in different computational models [30-32] provide reliable information about environmental behaviour of newly synthesis compound with a lack of experimental data. Our study's focus is to predict the influence of the chemical structure towards environmental behaviour of the non-radioactive part of radiopharmaceutical residuals as potential environmental vectors for conjugated radioisotopes. Estimation Programs Interface (EPI) Suite ${ }^{\mathrm{TM}}$ based set of physical/chemical property and environmental fate estimation programs developed by OPPT to screen new chemicals lacking experimental data was used to generate data for multivariate statistics analysis. In this way, it is possible easy but reliable prediction of partitioning, hazards and biodegradation of studied compounds.

\section{Materials and methods}

\section{Data set}

The dataset consists of 11 molecules - tetrazine derivatives and 12 molecules cyclooctene derivatives (see supplementary Table A1). All of these bifunctional moieties are non-radioactive parts of modern radiopharmaceuticals responsible for pharmacokinetics and conjugation, able to provide click reaction between each other and bio conjugate through oxime, hydrazone or peptide bonding $[33,34]$. In the set molecule from $\mathrm{C} 1$ to $\mathrm{C} 15$ are newly synthesized and the rest are commercially available (see supplementary Table A1). Each molecule in the present study was characterized by 24 parameters, namely molecule weight, $\mathrm{Mw}$, melting point, $\mathrm{Mp}$, boiling point, $\mathrm{Bp}$, water solubility, WS, vapour pressure, Vp and Henry's law constant HLC, as well as logarithms of partitioning constants between octanol and air, $\log K_{\mathrm{oa}}$, octanol and water, $\log K_{\mathrm{ow}}$, octanol soil, $\log K_{\mathrm{oc}}, \log$ arithm of bioconcentration factor, $\log B C F$, $\log$ arithm of bioaccumulation factor, $\log B A F$, fugacity in air, $F A$, fugacity in water, $F W$, fugacity in soil, $F S o$, fugacity in sediment, $F S e$, total removal, $T r$, total biodegradation, $T b$, total sludge adsorption, $T s a$ and biodegradation 
models: BIOWIN 1, BIOWIN 2, BIOWIN 3, BIOWIN 4, BIOWIN 5, BIOWIN 7. These parameters were calculated with models described in section modelling.

\section{Multivariate statistics}

Hierarchical clustering, $\mathrm{HC}$, aims to collect groups of similar objects within different data sets, which requires three basic steps to implement the clustering algorithm: standardization of raw data (to avoid the effect of different dimensional parameters); determining the distance between the grouping objects (in order to introduce a measure of similarity) and the connection procedure. The processing of different data sets is an important approach to objective decision making.

K-means clustering is a supervised method of Multivariate statistics and the final output is to partition the objects into $\mathrm{n}$ clusters in which each observation belongs to the cluster with the nearest mean (cluster centres or cluster centroid). Normally with the unsupervised technique we are checking the stated hypothesis for the number of formed clusters.

Principal component analysis, PCA, is a mathematical processing of the input data matrix, the aim of which is to study models in complex data sets, allowing to classify the information and to find a structure in a diffuse data set. The PCA limits the size of the input matrix X to two parts - A matrix (factor loads) and F matrix (factor estimates). Matrix A contains information about the weights of each variable in each identified new hidden factor, and as the higher are these values, the greater the contribution of the primary variables and allows to identify which variables affect the objects.

\section{Modelling - EPI Suite ${ }^{\mathrm{TM}}$}

In the present study the program EPI Suite ${ }^{\mathrm{TM}}$ version 4.10 was used which is available from the US Environmental Protection Agency [35]. This is a Windows ${ }^{\circledR}$-based data set of physical and chemical properties and environmental state assessment programs developed by the OPPT to screen for new chemicals that lack experimental data. The following subprograms of EPI Suite ${ }^{\mathrm{TM}}$ version 4.10 were used: KOWWIN ${ }^{\mathrm{TM}}$, MPBPVP ${ }^{\mathrm{TM}}$, WATERNT $^{\mathrm{TM}}$, HENRYWIN ${ }^{\mathrm{TM}}$, KOAWIN ${ }^{\mathrm{TM}}$, BIOWIN $^{\mathrm{TM}}, \mathrm{KOCWIN}^{\mathrm{TM}}$, BCFBAF $^{\mathrm{TM}}$, STP Removal and Fugacity.

The KOWWIN ${ }^{\mathrm{TM}}$ program calculates the octanol-water partition coefficient. KOWWIN uses a "fragment constant" methodology to predict $\log P$, where the structure is divided into atoms or larger functional groups and the values of the coefficients of each fragment are summed to obtain a $\log P$ estimate. According to $\log K_{\text {ow }}$ values for a specific chemical, its solubility in water or in fats / lipids is defined. According to EPI Suite ${ }^{\mathrm{TM}}$, the ranges of $\log K_{\mathrm{ow}}$ are: $<1$ highly soluble in water (hydrophilic); $>4$ not very soluble in water (hydrophobic); $>8$ are not readily bioavailable; $>10$ are not bioavailable.

The MPBPWIN estimates the boiling point, melting point and vapour pressure of organic compounds. The determination of boiling point has been done by modified the Stein and Brown method [36]. The melting point is calculated by two different methods: The Joback Group Contribution Method, and the Gold and Ogle method [37, 38]. The vapour pressure is defined by three methods: the Antoine method; the modified Grain method; the Mackay method [39]. According to the values of MP, BP and VP, the physical state of the chemical can be assessed by EPI Suite ${ }^{\mathrm{TM}}$ as follow: MP $<25{ }^{\circ} \mathrm{C}$ assessed as a liquid; MP $>25{ }^{\circ} \mathrm{C}$ assessed as a solid; $\mathrm{BP}<25^{\circ} \mathrm{C}$ assessed as a gas; VP $>10^{-4}$ exists mostly in the vapour (gas) phase; VP $10^{-5}-10^{-7}$ exists in the vapour and particulate phase; 
VP $<10^{-8}$ exists mostly in the solid phase. The physical state is an important indication of the distribution into the environment (air, water, biota, soil) of the released chemical.

The WATERNT program in EPI Suite ${ }^{\mathrm{TM}}$ use the same "fragment constant" methodology as for $\log P$ to predict water solubility. To obtain the coefficients for the individual groups in WATERNT, a multiple regression of 1000 reliably measured values of solubility in water was made. According to EPI Suite ${ }^{\mathrm{TM}}$ the following classifications, based on WS $\left[\mathrm{mg} / \mathrm{dm}^{3}\right]$, are made: > 10,000 very soluble; > 1,000-10,000 soluble; $>$ 100-1,000 moderate solubility; $>0.1-100$ slightly soluble and $<0.1$ insignificant solubility. The WS provides basic information on the entry, movement and release of chemicals between different parts of the environment.

The HENRYWIN program calculates the Henry's Law Constant, HLC, of organic compounds at $25{ }^{\circ} \mathrm{C}$ using two different methods: bond contribution; group contribution. The HLC $\left[\mathrm{Pa} \cdot \mathrm{m}^{3} / \mathrm{mole}\right]$ values in EPI Suite ${ }^{\mathrm{TM}}$ present the following information for the molecules: > $10^{-1}$ very volatile from water; $10^{-1}-10^{-3}$ volatile from water; $10^{-3}-10^{-5}$ moderately volatile from water; $10^{-5}-10^{-7}$ slightly volatile from water; $<10^{-7}$ nonvolatile.

The KOAWIN compute the Octanol-Air Partition Coefficient, $K_{\text {oa, of an organic }}$ compound by the compound's $K_{\mathrm{ow}}$ and HLC. $K_{\mathrm{oa}}$ is the ratio of a chemical partitioning between octanol and air at equilibrium. It is giving information for distribution behaviour of moieties between air and environmental parts such as soil, vegetation, and aerosol particles.

The KOCWIN programs calculate the soil adsorption coefficient, $K_{\mathrm{OC}}$, of organic compounds. $K_{\mathrm{OC}}$ can be described like the concentration of chemical adsorbed per unit weight of organic carbon, OC, in the soil to the amount of the chemical in solution at equilibrium as distribution ratio [40]. $K_{\mathrm{oc}}\left[\mathrm{dm}^{3} / \mathrm{kg}\right]$ or $\left[\mathrm{cm}^{3} / \mathrm{g}\right]$ represent information about chemical partition between solid and solution phases in soil, or between water and sediment in aquatic ecosystems [41]. The $\log K_{\text {oc }}$ values in EPI Suite ${ }^{\mathrm{TM}}$ provide the following information about the chemical: $>4.5$ very strong sorption to soil/sediment, negligible migration to ground water; 3.5-4.4 strong sorption to soil/sediment, negligible to slow migration to ground water; 2.5-3.4 moderate sorption to soil/sediment, slow migration to ground water; 1.5-2.4 low sorption to soil / sediment, moderate migration to ground water; $<1.5$ negligible sorption to soil/sediment, rapid migration to ground water.

The BCFWIN program methodology is described in Meylan and Howard [41]. The BCFBAF method classifies a compound as either ionic or non-ionic. The ionic substances were further divided into four groups: carboxylic acids; sulfonic acids; sulfonic salts; quaternary $\mathrm{N}$ compounds. The nonionic $\log B C F$ values are determinate from $\log K_{\mathrm{ow}}$ with a series of correction factors specific to each chemical. According EPI Suite ${ }^{\mathrm{TM}}$ program chemicals with a high $B C F$ are less water soluble and are expected to bioconcentrate in aquatic organisms. Conversely, low $B C F$ indicates higher water solubility with $\log B C F-\geq 3.7$ high bioconcentration potential; 3 moderate bioconcentration potential; $<3$ low bioconcentration potential.

The degradation of a chemical substance by the action of microorganisms (biodegradation), is estimated by EPI Suite ${ }^{\mathrm{TM}}$ using seven models include in BIOWIN program. Biodegradation can occur in the presence or absence of oxygen, for example fust aerobic biodegradation occurs in the upper surface water and soil levels and slow anaerobic biodegradation occurs in ground water and sediment. The rapid biodegradation under aerobic conditions in EPI Suite ${ }^{\mathrm{TM}}$ is evaluate by two models BIOWIN 1 (linear) and 
BIOWIN 2 (nonlinear) and data for both give information about speed of these processes: $>0.50$ Likely to biodegrade rapidly; < 0.50 Not likely to biodegrade rapidly. Biodegradation programs BIOWIN 3 (ultimate) present biodegradation to the complete mineralization of the molecule and BIOWIN 4 (primary) present biodegradation with change in the molecular structure to form a new compound. According obtained values for BIOWIN 3 and BIOWIN 4 in EPI Suite ${ }^{\mathrm{TM}}$ the presented time intervals are accept: $>$ 4.75-5 hours; > 4.25-4.75 hours - days; > 3.75-4.25 days; > 3.25-3.75 days - weeks; $>$ 2.75-3.25 weeks; > 2.25-2.75 weeks - months; > 1.75-2.25 months; < 1.75 longer. Ministry of International Trade and Industry in Japan (MITI) provides multiple linear or non-linear regression analyses on more than 800 chemicals to define biodegradation probability based on fragment constants that were include in EPI Suite ${ }^{\mathrm{TM}}$ program as BIOWIN 5 (MITI linear) and BIOWIN 6 (MITI nonlinear) and for both: > 0.50 Likely to biodegrade rapidly; < 0.50 Not likely to biodegrade rapidly. Anaerobic biodegradation values are calculated by BIOWIN 7 model where values: > 0.50 Likely to biodegrade rapidly; < 0.50 Not likely to biodegrade rapidly.

The fugacity model in EPI Suite ${ }^{\mathrm{TM}}$ is a level III multimedia fate model using environmental parameters identical to those used in Mackay et al. and predict the partitioning of an organic compound in an evaluative environment [43]. The model environment consists of 4 main compartments: the air; the water; the sediment; the soil. There are also subcompartments such as an aerosol phase, suspended solids, and biota phase, within specific main compartments. A fixed temperature of $25{ }^{\circ} \mathrm{C}$ is assumed. Mass transport between the compartments via volatilization, diffusion, deposition and runoff are modelled.

The STPWIN program in EPI Suite ${ }^{\mathrm{TM}}$ is a version of the Sewage Treatment Plant, STP Model based on fugacity principles originally developed by Mackay and co-workers at the University of Toronto (Canada) [43]. The STP Model predicts the behaviour of chemical in a conventional WWTP that uses activated sludge secondary treatment. The model determines the partitioning of a chemical present in the influent as it becomes subject to removal by evaporation, biodegradation or other degradation processes, sorption to sludge, and loss in the final effluent.

\section{Results and discussion}

The first step was the calculation of the values for Mw, Mp, Bp, WS, Vp, HLC, $\log K_{\mathrm{oa}}$, $\log K_{\mathrm{ow}}, \log K_{\mathrm{oc}}, \log B C F, \log B A F, F A, F W, F S o, F S e, T r, T b, T s a$, BIOWIN 1, BIOWIN 2 , BIOWIN 3, BIOWIN 4, BIOWIN 5 and BIOWIN 7, as described in the previous section. To find the internal patterns existing in the group of bifunctional compounds, HC and PCA were applied. These techniques were used for clustering of the chemical variables. The aim of the multivariate statistical analysis is to reveal hidden relationships between the objects and variables, to clarify the data structure and, additionally, to try to explain the relationships found with possible environmental impacts caused by the application of the newly synthesized molecules.

\section{Hierarchical cluster analysis}

In the new data set the matrix dimension is [23x23], i.e. 23 objects (molecules) and 23 descriptors (variables). 


\section{Descriptors clustering}

Three major clusters are formed (Fig. 1):

- $\quad \mathbf{C 1}$ (Fig. 1 - Mw, FSe, Bp, Mp, $\log K_{\text {oa }}$ WS, BIOWIN 7, BIOWIN 1, BIOWIN 2)

In cluster $\mathrm{C} 1$ (Fig. 1) one could find linkage between all physicochemical parameters, $\log$ Koa and the respective ecotoxicity tests BIOWIN 1, BIOWIN 2 and BIOWIN 7. In general, BIOWIN 1, BIOWIN 2 and BIOWIN 7 factors gave information about condition of biodegradation process with or without oxygen where BIOWIN 1 and BIOWIN 2 are responsible for aerobic degradation and BIOWIN 7 for anaerobic. Physicochemical parameters $\mathrm{Mw}, \mathrm{Bp}$ and $\mathrm{Mp}$ gives information about the physical state of chemicals and defines a major path for spreading into the ecosystem. Parameters such as WS, $\log K_{\mathrm{oa}}$ and fugacity sediment are connections between physical factors and a type of biodegradation, because they show the exact way of movement in environment. It might be concluded that the cluster represents a factor which relates a certain type of ecotoxicity with the physicochemical nature of the objects (new molecules) - "ecotoxicity to physical properties" environmental impact.

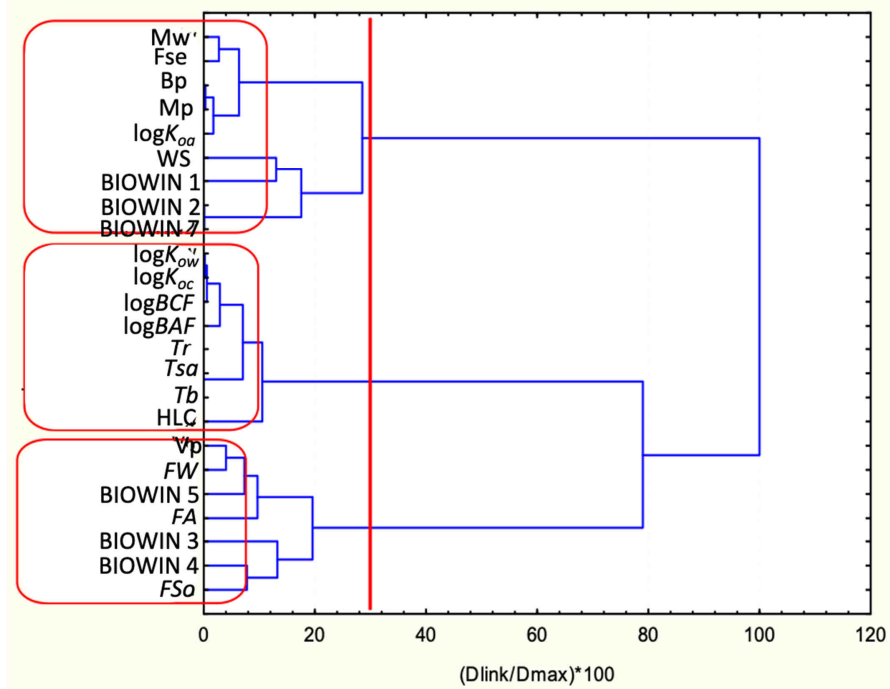

Fig. 1. Hierarchical dendrogram for clustering of descriptors

- $\quad \mathbf{C 2}$ (Fig. $\left.1-\log K_{o w}, \log K_{\mathrm{oc}}, \log B A F, \log B C F, T r, T s a, T b, \mathrm{HLC}\right)$

The second cluster (Fig. 1) includes descriptors related to the different distribution properties of the molecules and processes of degradation and adsorption in the environment. Descriptors as total removal, total sludge adsorption and total biodegradation gave information about partitioning and efficiency in sewage treatment plants. This has great importance for the ability to be effectively hold or degrade chemical pollutants and descriptors such as $\log K_{\mathrm{ow}}, \log K_{\mathrm{oc}}, \log B A F, \log B C F$ and HCL are needed to describe the distribution of reagents between air, water and sludge. No ecotoxicity indicators are included so that this cluster represents a "distribution and degradation" factor.

- $\quad \mathbf{C 3}$ (Fig. 1 - Vp, FW, FA, FSo, BIOWIN 5, BIOWIN 4, BIOWIN 3) 
The third cluster (Fig. 1) presents only one physicochemical parameter Vp which describe air as main source for relies of volatile chemicals in the other parts of the ecosystem. The rest of the descriptors evaluate the ability of chemicals to move into biospheres (atmosphere, lithosphere and hydrosphere), pass through its parts (all fugacity descriptors) and evaluate biodegradation model ultimate or primary. This cluster links together all types of fugacity to different environmental compartments, except for sediments, and three other ecotoxicity tests: "ecotoxicity to fugacity properties" environmental impact.

\section{Objects clustering}

If the three major cluster formed are considered it could be found that (Fig. 2):

- $\quad \mathbf{C 1}$ (see Table A1 in supplementary 1, 2, 4, 5, 17, 22, 19, 18, 20, 16, 21) includes 11 members - 4 from the newly synthesized molecules and 7 from the standard analog molecules (real molecules), so the new objects 1, 2, 4, 5 correspond to 17-22 added to the list.

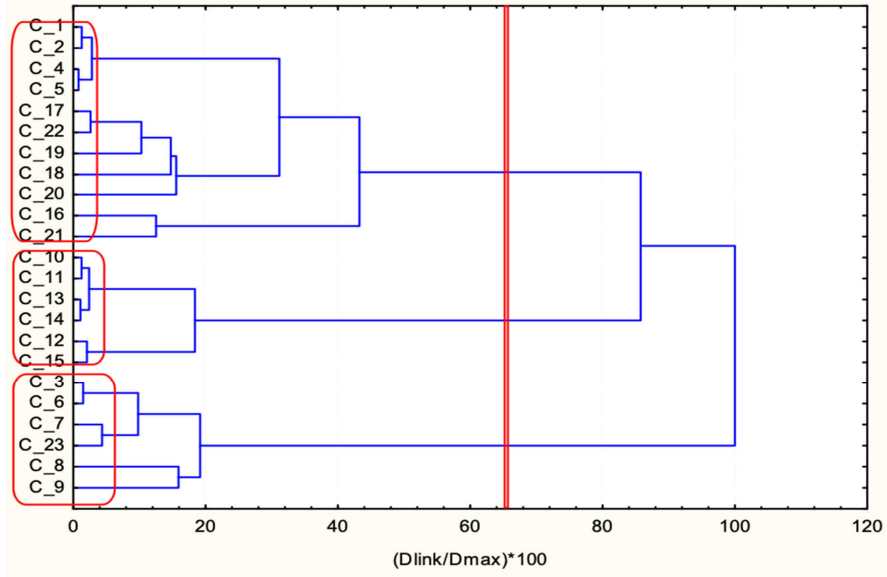

Fig. 2. Hierarchical dendrogram for clustering of molecules (objects)

The molecules in $\mathbf{C 1}$ cluster (Fig. 2) characterized with low value of fugacity sediment descriptor and all are water soluble - C1, C2, C3, C4 (new) are slightly to moderate soluble and the rest (commercially available) members of the group are soluble to very soluble. In this group the most probable molecules will go under aerobic biodegradation. Concerning ibuprofen, IBP, naproxen, NPX, and sulfamethoxazole, SMX, Khan and Ongerth [44] reported that $50 \%$ IBP, $55 \%$ NPX and $22 \%$ SMX are biologically degraded in the aeration tank of WWTP.

- C2 (see Table A1 in supplementary 10-15) consists of only newly synthesized 6 molecules, no analogs with newly added to the list.

Compound in $\mathbf{C 2}$ series (Fig. 2) has a similar chemical structure (homologues), all are nonvolatile solids which can be separated from other moieties by their lowest Henri's low constants. They also are characterized with low bioconcentration potential and have negligible, low or moderate sorption to soil $\left(\log K_{\mathrm{oc}}\right)$ which is premise for rapid, moderate or 
slow migration to the ground water. Carballa et al. report about $40 \%$ of the initial load of pharmaceuticals passes through the STP unaltered, with the fraction associated to sludge lower than $0.5 \%$ [20]. The dissociation constant (measures the propensity of a larger object to separate (dissociate) reversibly into smaller components) $K_{\mathrm{d}}$ value obtained in this study for IBP is in the same range as calculated from as $\log K_{\mathrm{oc}}$ in $\mathbf{C 2}$ series. Members of this cluster will present challenges for sewage treatment plants due to their low percentage of total removal at the end of treatment.

- $\quad$ C3 (see Table A1 in supplementary 3, 6-9, 23) indicates the resemblance between 5 newly synthesized molecules and one standard one added to the list.

All molecules in this C3 cluster (Fig. 2) have structural similarity due to cyclooctene ring and hydrocarbon chain which define their high lipophiles and will tend to bioconcentrate in organisms. The group characterize also with primary (BIOWIN 3) biodegradation of compounds in days-weeks, ultimate (BIOWIN 4) biodegradation in weeks-months and deposition in soil (fugacity descriptors). Representative of this cluster will cause long term effect over the ecosystem due to their specific fixation into the soil. Between 20 and $40 \%$ of the initial load of musks leaves the STR associated to solids, with less than $10 \%$ present in the final effluent was reported by Simonich et al. [45].

It might be concluded that the introduced standards show good similarity to the intended new molecules.

\section{Determination of descriptors for the identified clusters}

In this plot (Fig. 3) it is readily seen which descriptors are responsible for the formation of each cluster of objects (molecules) - see Table A2, A3 and A4 in supplementary.

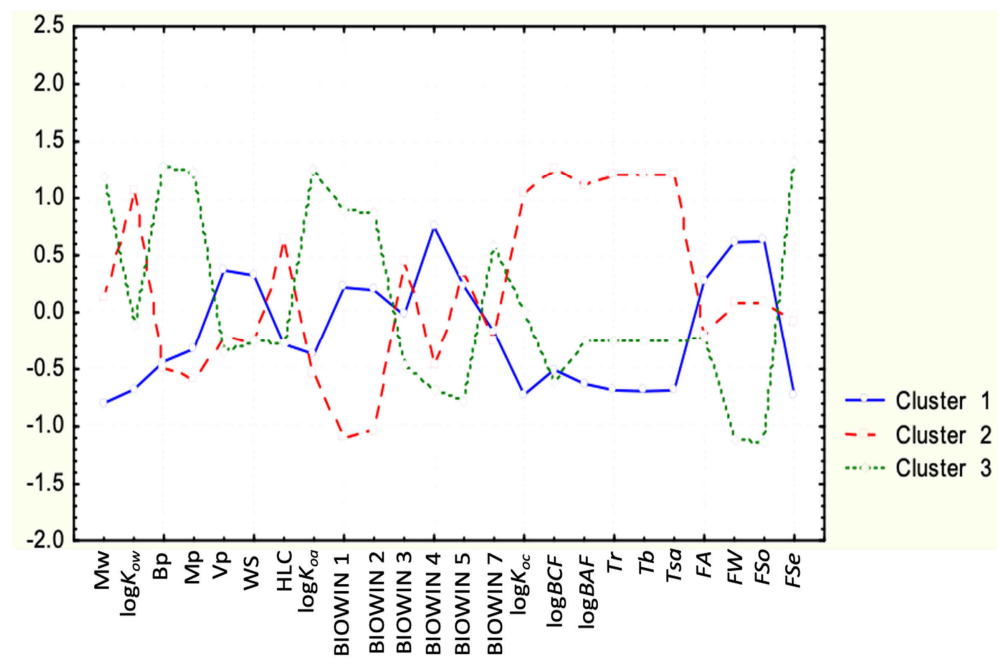

Fig. 3. Plot of means of all objects within a cluster for each descriptor

For instance, the grouping of the 10 objects in cluster 1 is due to the highest values of BIOWIN 4, fugacity in air, water and soil, water solubility. It might be assumed that the ecotoxicity of the group is the result of good water solubility and "high" fugacity 
(exchange) to air, water and soil. Further, low removal characteristics will probably play an important role to higher ecotoxicity.

The relatively enhanced ecotoxicity for the objects in cluster 2 is related to the highest values of the partitioning coefficients, removal and degradation properties.

The objects in cluster 3 are characterized by enhanced indication of ecotoxicity (BIOWIN 1-3) due to specific physicochemical properties of the target molecules.

\section{Factor analysis}

In Table 1 and Figure 4 the results of the factor analysis and the relationships between the descriptors on the plane of factor 1 and factor 2 are presented. Three latent factors explain over $75 \%$ of the total variance and the clustering of variables results is generally confirmed by PCA results.

Factor loadings (the highest loadings are marked by bold)

Table 1

\begin{tabular}{|c|c|c|c|}
\hline Variables & Factor 1 & Factor 2 & Factor 3 \\
\hline Mw & -0.375 & 0.766 & 0.453 \\
\hline $\log K_{\text {ow }}$ & -0.961 & 0.008 & 0.028 \\
\hline Bp & 0.141 & 0.812 & 0.495 \\
\hline $\mathrm{Mp}$ & 0.258 & 0.801 & 0.477 \\
\hline $\mathrm{Vp}$ & 0.198 & -0.836 & 0.259 \\
\hline WS & 0.346 & -0.047 & -0.158 \\
\hline Henry law & -0.579 & -0.073 & -0.128 \\
\hline $\log K_{\text {oa }}$ & 0.133 & 0.800 & 0.450 \\
\hline BIOWIN1 & 0.681 & 0.087 & 0.609 \\
\hline BIOWIN2 & 0.657 & 0.024 & 0.623 \\
\hline BIOWIN3 & -0.248 & -0.304 & -0.282 \\
\hline BIOWIN4 & 0.556 & -0.407 & -0.216 \\
\hline BIOWIN5 & -0.198 & -0.776 & 0.027 \\
\hline BIOWIN7 & 0.086 & 0.512 & 0.097 \\
\hline $\log K_{\mathrm{oc}}$ & -0.959 & 0.076 & 0.048 \\
\hline $\log B C F$ & -0.882 & -0.181 & -0.322 \\
\hline $\log B A F$ & -0.969 & -0.025 & -0.017 \\
\hline$T r$ & -0.938 & -0.000 & 0.051 \\
\hline$T b$ & -0.939 & 0.006 & 0.056 \\
\hline$T s a$ & -0.938 & 0.001 & 0.052 \\
\hline$F A$ & 0.220 & -0.622 & 0.294 \\
\hline$F W$ & 0.180 & -0.881 & -0.309 \\
\hline FSo & 0.288 & -0.144 & -0.895 \\
\hline$F S e$ & -0.295 & 0.514 & 0.770 \\
\hline Expl. var [\%] & 35.4 & 24.4 & 14.9 \\
\hline
\end{tabular}

Latent factor 1 (explanation of the total variance 35.4\%) indicates the strong correlation between a big group of ecotoxic and WWTP indicators $\left(\log K_{\mathrm{oc}}, \log B C F\right.$, $\log B A F$, Total removal, Total biodegradation and Total sludge adsorption) with the calculated values of $\log K_{\mathrm{ow}}$ and Henry law. Thus, it coincides entirely with cluster C2 (Fig. 1) and PC1 (Fig. 4) and could be conditionally named "ecotoxicity impact related to degradation, distribution and accumulation processes". These descriptors very well explain formation of C2 (10-15) object cluster (Fig. 2) and could be used for predicting efficiency of degradation and retention of RPR in WWTP. Also, a negative correlation between BIOWIN 1, BIOWIN 2 and the above-mentioned descriptors has been found. Having in 
mind that BIOWIN 1 and BIOWIN 2 describe biodegradation under aerobic conditions it is very logical to expect that compounds with low accumulation ability will stay principally into water phase where aerobic biodegradation is the most probable. This is the probable reason in PCA BIOWIN 1 and BIOWIN 2 to form separate group PC2 which describe very well molecules in C1 (see Table A1 in supplementary 1, 2, 4, 5, 17, 22, 19, 18, 20, 16, 21) object cluster (Fig. 2).

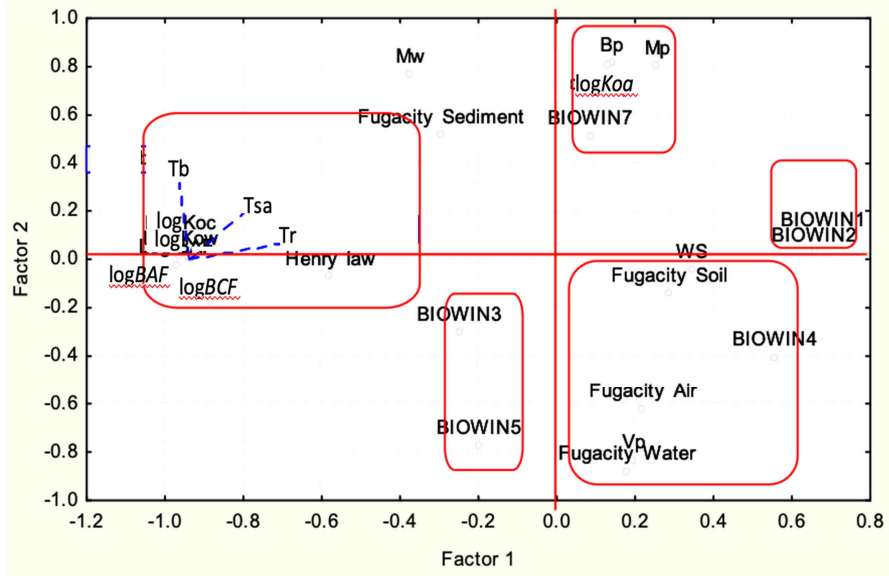

Fig. 4. Biplot factor 1 vs. factor 2

Latent factor 2 (24.4\% explanation of the total variance) show good correlation between fundamental physicochemical descriptors $\left(\mathrm{Bp}, \mathrm{Mp}, \log K_{\mathrm{oa}}\right)$ and biodegradation descriptor B7 which form separate group PC3 in PCA plot and could be conditionally named "ecotoxicity impact related to physicochemical properties". This group of descriptors can be used to defined moieties with preferable anaerobic biodegradation. Descriptors BIOWIN 3 and BIOWIN 5 have a good relationship and form separate group in PCA plot (PC4). It indicates the specific importance of BIOWIN 3, BIOWIN 5 as discriminant for general biodegradability of data set. PC5 group include descriptors Vp, WS, B4, FA, Fugacity Water and Fugacity Soil which correlate between each other and resume cluster C3 (Fig. 1) and C3 (see Table A1 in supplementary 3, 6-9, 23) object cluster (Fig. 2.).

Latent factor 3 (explained variance $14.9 \%$ ) could be find that the variable FSo and FSe are not directly connected with other variables. It is readily seen that the fugacity soil is negatively correlated to the fugacity sediments, and this is a difference to the clustering in Figure 1. But this relationship does not seem unusual, and this latent factor could be conditionally named "ecotoxicity impact related to soil and sediment fugacity".

\section{Conclusion}

The cluster analysis and PCA were used to group bifunctional molecules according to their similarity pattern. Variables were grouped with principal component analysis and cluster analysis to assess and identify from which properties values environmental impact can be predicted. The results show that values of physicochemical parameters as $\mathrm{Mw}, \mathrm{Bp}$ 
and $\mathrm{Mp}$ for the set of explored compounds can be predicted based on QSPR properties of the molecules. Thus, these estimations will enable the identification of the ecological effect of radiopharmaceutical residual for which experimental values are not yet available. As in any statistical and theoretical approach for modelling the limitations are related to percentage of model validity which in this case is above $75 \%$.

\section{Acknowledgments}

The author Boyan Todorov is thankful for the financial support for the article proceeding charges by National Science Fund, Bulgarian Ministry of Education and Science (contract No. KP-06-H29/4).

The author Miroslava Nedyalkova is grateful for the additional support by the project "Information and Communication Technologies for a Single Digital Market in Science, Education and Security" of the Scientific Research Center, NIS-3317 and National roadmaps for research infrastructures (RIs) grant number [NIS-3318].

\section{References}

[1] Sammut BN, Azzopardi LM, Serracino-Inglott A. Early Human Development. 2020;0378-3782:105218. DOI: 10.1016/j.earlhumdev.2020.105218.

[2] Kümmerer K. Annual Rev Environ Resources. 2010;35(1):57-75. DOI: 10.1146/annurev-environ-052809-161223.

[3] Ilem-Ozdemir D, Atlihan GE, Ekinci M, Ozgenc E, Asikoglu M. Biomedical Appl Nanoparticles. 2019:457-90. DOI: 10.1016/b978-0-12-816506-5.00017-6.

[4] Cutler CS, Bailey EA, Kumar V, Schwarz SW, Bom HH-S, Hatazawa J. J Nuclear Medicine. 2020;120:247197. DOI: 10.2967/jnumed.120.247197.

[5] Zanzonico PB, Siegel JA, St Germain J. Health Phys. 2000;78(6):648-59. DOI: 10.1097/00004032-200006000-00007.

[6] Andersson M, Johansson L. Mattsson S. Minarik D. Leide-Svegborn S. Radiation Protection Dosimetry. 2016;169(1-4):253-8. DOI: 10.1093/rpd/ncw033.

[7] Mulas D, Camacho A, Garbayo A, Devesa R, Duch MA. Sci Total Environ. 2019;663(0048-9697):818-29. DOI: 10.1016/j.scitotenv.2019.01.349.

[8] Martínez J, Peñalver A, Baciu T, Artigues M, Danús M, Aguilar C, et al. J Environ Radioact. 2018;192(0265-931X):187-93. DOI: 10.1016/j.jenvrad.2018.06.024.

[9] Hormann V, Fischer HW. J Environ Radioactivity. 2017; 178-179(0265-931X):55-62. DOI: 10.1016/j.jenvrad.2017.07.008.

[10] Malta M, Oliveira JM, Silva L, Carvalho FP. Revista de Gestão Costeira Integrada. 2013;13(4):399-408. DOI: $10.5894 / \mathrm{rgci} 339$.

[11] Fischer HW, Ulbrich S, Pittauerová D, Hettwig B. J Environ Radioact. 2009;100(12):1079-85. DOI: 10.1016/j.jenvrad.2009.05.002.

[12] Nakamura A, Hayabuchi N, Osaki T, Osaki S. Health Phys. 2005;88(2):163-8. DOI: 10.1097/01.hp.0000144577.34056.98.

[13] Chang HS, Xu C, Schwehr KA, Zhang S, Kaplan DI, Seaman JC, et al. J Environ Chem Eng. 2014;2(3):1321-30. DOI: 10.1016/j.jece.2014.03.009.

[14] Hormann V, Fischer HW. Environ Sci Tech. 2018;52(16):9235-42. DOI: 10.1021/acs.est.8b01553.

[15] Sarko D, Eisenhut M, Haberkorn U, Mier W. Cur Med Chem. 2012;19(17):2667-88. DOI: 10.2174/092986712800609751.

[16] Kopka K. Pharmaceuticals. 2014;7(7):839-49. DOI: 10.3390/ph7070839.

[17] Kozempel J, Vlk M, Nykl P, Psondrova S, Smrcek S, Krmelova T. Environmental Aspects of Radiopharmaceuticals Extraction and Translocation of Ra223 in Plants. ${ }^{\text {th }}$ Int Conf Adv Civil, Structural Environ Eng - ACSEE 2016. 2016;978-1-63248-114-6. DOI: 10.15224/978-1-63248-114-6-27.

[18] Rose PS, Smith JP, Cochran JK, Aller RC, Swanson RL. Sci Total Environ. 2013;452-453(0048-9697):87-97. DOI: 10.1016/j.scitotenv.2013.01.055.

[19] Fatta-Kassinos D, Meric S, Nikolaou A. Anal Bioanal Chem. 2010;399(1):251-75. DOI: 10.1007/s00216-010-4300-9. 
[20] Carballa M, Omil F, Lema JM. Environ Sci Technol. 2007;41(3):884-90. DOI: 10.1021/es061581g.

[21] Oliveira BL, Guo Z, Bernardes GJL. Chem Soc Rev. 2017;46(16):4895-950. DOI: 10.1039/c7cs00184c.

[22] Lyubimenko R, Richards BS, Turshatov A, Schäfer AI. Sci Rep. 2020;10(1). DOI: 10.1038/s41598-020-63697-y.

[23] Ibrahim HS, Allam HA, Mahmoud WR, Bonardi A, Nocentini A, Gratteri P, et al. Eur J Medic Chem. 2018;152:1-9. DOI: 10.1016/j.ejmech.2018.04.016.

[24] Box K, Comer J. Curr Drug Metab. 2008;9(9):869-78. DOI: 10.2174/138920008786485155.

[25] Oz N, Topal B, Uzun HI. Ecol Chem Eng S. 2019;26(4):727-42. DOI:10.1515/eces-2019-0051.

[26] Mackay D, Arnot JA, Celsie A, Orazietti A. SAR QSAR Environ Res. 2014;25(5):343-55. DOI: 10.1080/1062936x.2014.900521.

[27] Kozerski GE, Xu S, Miller J, Durham J. Environ Toxicol Chem. 2014;33(9):1937-45. DOI: 10.1002/etc.2640.

[28] Vitoratos A, Fois C, Danias P, Likudis Z. Water Air Soil Pollut. 2016;227(11). DOI: 10.1007/s11270-016-3076-8

[29] Wang Y, Chen J, Yang X, Lyakurwa F, Li X, Qiao X. Chemosphere. 2015;119:438-44. DOI: 10.1016/j.chemosphere.2014.07.007.

[30] Pandey SK, Roy K. Ecotox Environ Saf. 2021;208:111411. DOI: 10.1016/j.ecoenv.2020.111411.

[31] Chen D, Wang Q, Li Y, Li Y, Zhou H, Fan Y. Chemosphere. 2020;247:125869. DOI: 10.1016/j.chemosphere.2020.125869.

[32] Tobiszewski M, Nedyalkova M, Madurga S, Pena-Pereira F, Namieśnik J, Simeonov V. Ecotox Environ Saf. 2018;147(0147-6513):292-8. DOI: 10.1016/j.ecoenv.2017.08.057.

[33] Keinänen O, Brennan JM, Membreno R, Fung K, Gangangari K, Dayts EJ, et al. Mol Pharmaceutics. 2019;16(10):4416-21. DOI: 10.1021/acs.molpharmaceut.9b00746.

[34] Margison KD, Bilodeau DA, Mahmoudi F, Pezacki JP. ChemBioChem. 2020;21(7):948-51. DOI: 10.1002/cbic.201900627.

[35] EPI Suite ${ }^{\mathrm{TM}}$ - Estimation Program Interface. Available from: http://www.epa.gov/oppt/exposure/ pubs/episuite.htm.

[36] Stein SE, Brown RL. J Chem Infor Model. 1994;34(3):581-7. DOI: 10.1021/ci00019a016.

[37] Joback KG, Reid RC. Chem Eng Commun. 1987;57(1-6):233-43. DOI: 10.1080/00986448708960487.

[38] Dearden JC. Environ Toxicol Chem. 2003;22(8):1696-709. DOI: 10.1897/01-363.

[39] Lyman WJ, Reehl WF, Rosenblatt DH. Handbook of Chemical Property Estimation Methods: Environmental Behavior of Organic Compounds. United States: Am Chem Soc; 1996. ISBN: 6942967

[40] Bahnick DA, Doucette WJ. Chemosphere. 1988;17(9):1703-15. DOI: 10.1016/0045-6535(88)90098-7.

[41] Meylan WM, Howard PH, Boethling RS, Aronson D, Printup H, Gouchie S. Environ Toxicol Chem. 1999;18(4):664-72. DOI: 10.1002/etc.5620180412.

[42] Clark B, Henry GLH, Mackay D. Environ Sci Technol. 1995;29(6):1488-94. DOI: 10.1021/es00006a009.

[43] Mackay D, Paterson S, Shiu WY. Chemosphere. 1991;24(6):695-717. DOI: 10.1016/0045-6535(92)90531-U.

[44] Khan SJ, Ongerth JE. Chemosphere. 2004;54(3):355-67. DOI: 10.1016/j.chemosphere.2003.07.001.

[45] Simonich SL, Federle TW, Eckhoff WS, Rottiers A, Webb S, Sabaliunas D, et al. Environ Sci Technol. 2002;36(13):2839-47. DOI: 10.1021/es025503e. 